\title{
Corrigendum: The monogenic autoinflammatory diseases define new path- ways in human innate immunity and inflammation
}

Kalpana Manthiram, Qing Zhou, Ivona Aksentijevich \& Daniel L Kastner

Nat. Immunol. 18, 832-842 (2017); published online 19 July 2017; corrected after print 17 August 2017

In the version of this article initially published, the final sentence of the third paragraph of the first subsection ('Monogenic periodic fever syndromes') incorrectly states that "Colchicine causes microtubule destabilization, thereby facilitating pyrin-inflammasome activation independently of RhoA." That sentence should read: "Colchicine also causes microtubule destabilization, thereby inhibiting pyrin-inflammasome activation independently of RhoA." The error has been corrected in the HTML and PDF versions of the article.

\section{Corrigendum: IL-6 as a keystone cytokine in health and disease}

Christopher A Hunter \& Simon A Jones

Nat. Immunol. 16, 448-457 (2015); published online 21 April 2015; corrected after print 17 August 2017

In the version of this article initially published, some of the labels in Figure 4a,b were incorrect. In Figure 4a, in the group of IL-6 blockers (top right), 'ALX-0061' should be removed and 'Siltuximab' and 'MEDI 5117' should be added, and in the group of IL-6R blockers (middle right), 'Siltuximab' and 'ALD518' should be removed and 'ALX-0061' should be added. In Figure 4b, in the group of inhibitors at bottom left, 'MEDI 5517' should be revised to 'MEDI 5117. These errors have been corrected in the HTML and PDF versions of the article.

\section{Erratum: Gut microbial metabolites limit the frequency of autoimmune T cells and protect against type 1 diabetes}

Eliana Mariño, James L Richards, Keiran H McLeod, Dragana Stanley, Yu Anne Yap, Jacinta Knight, Craig McKenzie, Jan Kranich, Ana Carolina Oliveira, Fernando J Rossello, Balasubramanian Krishnamurthy, Christian M Nefzger, Laurence Macia, Alison Thorburn, Alan G Baxter, Grant Morahan, Lee H Wong, Jose M Polo, Robert J Moore, Trevor J Lockett, Julie M Clarke, David L Topping, Leonard C Harrison \& Charles R Mackay Nat. Immunol. 18, 552-562 (2017); published online 27 March 2017; corrected online 5 April 2017; corrected after print 8 May 2017

In the version of this article initially published, the graph curves in Figure 2b were displayed incorrectly. The error has been corrected in the HTML and PDF versions of the article. 